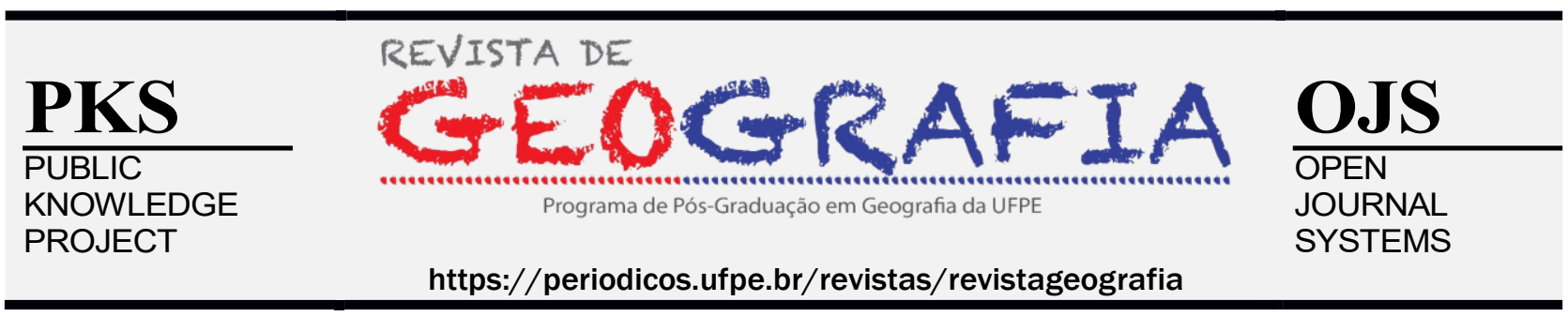

\title{
COMPREENDENDO A PANDEMIA DE COVID-19 A PARTIR DO CONHECIMENTOS GEOGRÁFICOS
}

\author{
Francisco Fernandes Ladeira ${ }^{1}$
}

'Doutorando em Geografia pela Universidade Estadual de Campinas - Unicamp. E-mail: ffernandesladeira@yahoo.com.br.ORCID: https://orcid.org/0000-0002-0004-8384

Artigo recebido em 09/05/2021 e aceito em 19/07/2021

\section{RESUMO}

O presente trabalho descreve uma prática pedagógica, realizada em uma escola da rede estadual da Bahia, em que conceitos e conteúdos trabalhados na disciplina de Geografia foram utilizados para analisar a dinâmica da pandemia da Covid-19, nomenclatura dada a doença causada pelo patógeno novo coronavírus (Sars-Cov-2). Para melhor organização da temática proposta, a aula em questão foi dividida em três tópicos: 1) Surgimento da Covid-19 na China; 2) Expansão da pandemia relacionada aos fluxos da globalização; 3) Covid-19 no Brasil: reflexo da segregação socioespacial. Contatamos que a experiência observada foi de grande valia para os alunos, pois aproximou a sala de aula a uma temática atual, relevante não apenas para a aprendizagem escolar, mas também para a formação cidadã dos educandos.

Palavras-chave: Covid-19; Geografia; Aula.

\section{UNDERSTANDING THE COVID-19 PANDEMIC FROM GEOGRAPHICAL KNOWLEDGE}

\begin{abstract}
The present work describe a pedagogical practice, held in a school in the state of Bahia, in which the concepts and content worked in the discipline of geography were used to analyze the dynamics of the Covid-19 pandemic, nomenclature given the disease caused by the new coronavirus pathogen (Sars-Cov-2). For a better organization of the proposed theme, the class in question was divided into three topics: 1) Emergence of the Covid-19 in China; 2) Expansion of the pandemic related to globalization flows; 3) Covid-19 in Brazil: a reflection of socio-spatial segregation. We found that the observed experience was of great value for students, as it brought the classroom closer to a current theme, relevant not only for school learning, but also for the citizens' education of students.
\end{abstract}

Keywords: Covid-19. Geography. Class. 


\section{INTRODUÇÃO}

No ano de 2020, todos os continentes do planeta foram afetados pela pandemia de Covid19, nomenclatura pela qual é designada a doença causada pelo novo coronavírus (Sars-Cov-2).

Entre as medidas emergenciais adotadas por autoridades governamentais com o objetivo de evitar a rápida propagação do novo coronavírus podemos citar a restrição de circulação de pessoas, a obrigatoriedade do uso máscaras em espaços público, o fechamento de serviços considerados não essenciais e a suspensão de aulas presenciais, afetando aproximadamente 1,5 bilhão de crianças e jovens em todo o mundo (UNICEF, 2020). Assim, surgiu uma nova modalidade de ensino: o ensino remoto, realizado virtualmente.

Mesmo com as aulas virtuais - num cenário em que "as fake news tomaram conta da Internet [...], fazendo com que as pessoas acreditassem e repassassem conteúdos que prejudicaram a ciência, especialistas, órgãos internacionais e de governos" (CUNHA, 2021, p. 50) - muitos alunos ainda concebiam seus professores como fontes confiáveis para melhor compreender os desdobramentos da pandemia de Covid-19.

De acordo com Ladeira (2020), particularmente no contexto pandêmico, a grande disseminação de fake news (notícias falsas) gerou pânico, superlotou unidades de saúde, provocou a falta de determinados produtos nas prateleiras dos supermercados, comprometeu atendimentos em hospitais. Em casos graves, levou a óbito indivíduos que se submeteram a tratamentos médicos ineficazes contra a Covid-19.

Nesse sentido, o presente artigo relata uma prática pedagógica em que conceitos e conteúdos trabalhados na disciplina de Geografia foram utilizados para analisar a dinâmica da pandemia da Covid-19. A experiência didática foi realizada numa turma de $3^{\circ}$ ano do ensino médio de uma escola da rede estadual da Bahia.

A aula em questão foi dividida em três tópicos: 1) Surgimento da Covid-19 na China; 2) Expansão da pandemia relacionada aos fluxos da globalização; 3) Covid-19 no Brasil: reflexo da segregação socioespacial.

O procedimento metodológico adotado foi o estudo de caso, a partir da observação direta da aula de Geografia ministrada, via Google Classroom. Segundo Ventura (2007), como instrumento de 
investigação, o estudo de caso é uma modalidade de pesquisa que pode ser aplicada em diversas áreas do conhecimento. Nas pesquisas em educação, o estudo de caso proporciona maior conhecimento para o pesquisador sobre um determinado assunto, permitindo a compreensão do cotidiano escolar como possibilidade de vivências únicas e impregnadas de sentido (GODOY, 1995; GIL, 1988).

Para preservar as identidades de alunos e professor de Geografia, optamos por não mencionar o nome da instituição escolar da classe observada.

\title{
$1^{\circ}$ TÓPICO: SURGIMENTO DA COVID-19 NA CHINA
}

No início da aula, o professor de Geografia informou aos alunos que, naquele horário, abordaria uma temática atual, bastante presente em conversações cotidianas e nos principais veículos de comunicação. Trata-se da pandemia de Covid-19, cujo primeiro epicentro foi a cidade de Wuhan, China. Posteriormente, a doença se espalhou por todo o planeta.

Segundo o professor, quando se fala em pandemia, por ser algo global, automaticamente, já remete à Geografia; disciplina que, entre outras questões, estuda o que se convencionou chamar de "mundo globalizado".

De acordo com o docente:

\begin{abstract}
Durante o último ano, praticamente só se falou na pandemia de Covid-19, causada pelo coronavírus. Muito se fala, muita desinformação sobre a situação, as chamadas fake news. $\mathrm{O}$ que eu trago para vocês é uma proposta de tentar compreender a pandemia a partir das temáticas que nós estudamos em Geografia. (...) A própria ideia de isolamento social (medida adotada para evitar a propagação do coronavírus) é geográfica. Você está 'isolado' num determinado espaço. A ideia de lockdown é diminuir a circulação no espaço geográfico. Como vocês estão no $3^{\circ}$ ano, as temáticas que eu vou mencionar vocês já conhecem.
\end{abstract}

No entanto, o professor frisou que "evidentemente, a Geografia, por si só, não vai explicar a pandemia. Precisamos também da Biologia, História, Química Sociologia (...)”. Nesse sentido, compete à ciência geográfica explicar a dinâmica da pandemia no espaço, como a doença de espalhou devido às caraterísticas físicas e humanas das diferentes regiões do planeta.

Posteriormente, foi observada a importância do conceito de "escala geográfica" para as definições de endemia, surto, epidemia e pandemia.

Em Geografia, uma das questões mais significativas ao tratar do que estudar diz respeito à escala de análise que será considerada. Ao estudar o espaço geográfico, a delimitação do mesmo é um passo necessário, pois o espaço é imenso, planetário, mundial. O que dele ou 
nele estudar? Para dar conta da delimitação deve-se fazer a referência à escala social [e geográfica] de análise, que, em seus vários níveis, encaminha a recortes que elegem determinada extensão territorial (CALLAI, 2014, p. 71).

Dessa forma, a ciência geográfica recorre ao conceito de "escala geográfica" para estudar fenômenos que podem ocorrer nos âmbitos local, regional, nacional e global.

A concepção de "endemia” está ligada à escala local, pois se refere a uma doença típica de uma região, em virtude de suas características naturais e sociais. Um surto também ocorre em âmbito local, porém com o aumento repentino do número de casos de uma doença. Para ser considerada como epidemia, uma doença deve ser identificada em escala nacional. Por fim, quando uma doença se espalha em âmbito continental ou global, passa a ser considerada "pandemia".

Após a explicação dos conceitos mencionados acima, um aluno, ao lembrar dos conteúdos estudados em Biologia, pediu a palavra:

A própria dengue, o mosquito transmissor, é de origem africana. Então, o processo de ocupação do homem nesse espaço, fez com que o mosquito viesse aqui para o Brasil, se colocasse nas matas, mas com o crescimento das cidades foi procurar outros espaços. Resultado: propagação da dengue (ALUNO).

Ao introduzir o primeiro tópico da aula -“"Surgimento da Covid-19 na China" - o professor destacou que o capitalismo é um sistema econômico baseado na produção e consumo em larga escala, o que requer, inevitavelmente, expansão para novos espaços. Nessa lógica, a China pode ser considerada como uma das últimas fronteiras vencidas pelo capital. Um país que, embora se mantenha politicamente governado pelo Partido Comunista, sob o aspecto econômico, está aberto para a economia de mercado.

Na década de 1970, quando a China, em grave crise, se abriu economicamente para o mundo, havia até uma frase emblemática: "Só o capitalismo pode salvar a China”. Ironicamente, após a crise financeira de 2007, inverteu-se a frase, dali em diante "só a China poderia salvar o capitalismo". (...) Os principais fluxos globais de mercadorias e capitais passam pela China. Difícil imaginar o atual andamento da economia planetária sem este gigante asiático (PROFESSOR DE GEOGRAFIA).

Em sequência, foi abordado o intenso processo de industrialização da China ocorrido nas últimas décadas. Quanto mais um país se industrializa, maior a necessidade de matéria-prima, logo aumenta a pressão sobre o meio ambiente. Segundo professor, "ao longo da história, epidemias estiveram associadas a novas áreas industriais (como é o caso da região de Wuhan)”. 
A partir de um gráfico, o docente mostrou para os alunos como o processo de urbanização chinesa foi intenso. Em 1960, somente 16\% dos habitantes do país residiam em cidades. Menos de sessenta anos depois, em 2017, a maioria (58\%) dos chineses estavam em áreas citadinas. Maior crescimento das cidades significa o aumento das possibilidades de contatos entre os espaços urbano e silvestre (onde há ecossistemas cujas espécies se relacionam em equilíbrio).

Com dúvidas sobre o conteúdo da aula, um aluno solicitou que o professor falasse um pouco mais sobre as caraterísticas populacionais da China, como "isso influenciou a propagação do coronavírus?".

Em resposta, o professor mencionou a irregular distribuição da população pelo território chinês, com a maioria dos habitantes se concentrando na fachada leste do país, onde estão localizadas as Zonas Economicas Especiais (ZEEs).

As ZEEs da China foram criadas pelo Governo Deng Xiaoping (1982-1987) e foram mantidas pelos governos ulteriores. Elas são consideradas como o principal marco da transição chinesa do comunismo (ou capitalismo de Estado, na visão de alguns especialistas) para o capitalismo de Economia de Mercado. (...) Consistem em áreas especificamente destinadas para o direcionamento da atividade industrial a partir do oferecimento de vantagens para atrair investimentos estrangeiros (MUNDO EDUCAÇÃO, s/d).

Retomando a explicação da matéria, o professor destacou que "quando o equilíbrio de determinado ecossistema é rompido pela ação antrópica, patógenos podem migrar de outras espécies animais para o ser humano". Este foi o caso do novo coronavírus, que, conforme sugerem estudos, chegou até nós através de morcegos (WONG et., 2019; ZHANG et al., 2020; ZHOU et al., 2020) ou pangolins (LIU et al., 2020 e XIAO et al., 2020).

\footnotetext{
É bem conhecido entre virologistas que morcegos (Chiroptera) são hospedeiros primários de grande variedade de grupos virais, e por seu sistema imunológico peculiar, lhes causam pouco ou nenhum dano à saúde (Li et al., 2005; Hu et al., 2015; Wong et al., 2019). Enquanto voam, morcegos depositam seus excrementos sobre o solo, prestando serviço essencial na dispersão de sementes; porém, nesse processo os morcegos portadores de coronavírus podem ter contaminado a área onde habitam; locais também utilizados por outras espécies, notavelmente pelos pangolins (gênero Manis; Liu et al., 2020). Esses mamíferos habitam florestas da África subsaariana e da Ásia, e se alimentam de formigas e cupins usando suas imensas unhas para escavar e sua língua pegajosa para capturar os insetos. Frequentemente procuram abrigo em cavidades de rochas, no solo, em troncos ocos e entradas de cavernas, locais também usados pelos morcegos. Esse compartilhamento de hábitat pode ter favorecido o spillover do coronavírus dos morcegos aos pangolins. Os pangolins são os animais silvestres mais traficados do planeta, e a China tem sido o maior financiador desse tráfico ilegal (ACOSTA et al., 2020, p. 192).
} 
Para o professor "quanto mais a paisagem humanizada - ou seja, o que é feito pelo ser humano - substitui a paisagem natural, maior contato entre ser humano e outras espécies, antes isoladas. Isso significa que aumentam as possibilidades de nós contrairmos determinados vírus".

Prontamente, uma aluna questionou: "Então, se continuar essa pressão humana sobre o meio ambiente, a tendência é que a gente tenha mais surtos, epidemias, endemias e pandemias? ”

O professor respondeu: "É uma questão a se pensar: que modelo de sociedade estamos produzindo?".

Desse modo, foi encerrado o primeiro tópico da aula de Geografia, propondo aos alunos uma reflexão sobre como o sistema econômico vigente produz grande degradação ambiental.

\section{$2^{\circ}$ TÓPICO: EXPANSÃO DA PANDEMIA RELACIONADA AOS FLUXOS DA GLOBALIZAÇÃO}

O segundo tópico da aula sobre a análise da pandemia de Covid-19 a partir dos conhecimentos geográficos teve início com a exibição de um mapa com a localização de Wuhan no território chinês. Os alunos puderam perceber que se trata de uma cidade bastante conectada com outras metrópoles, o que possibilitou a grande expansão do coronavírus pelo país. O professor ressaltou que "um dos fatores para espalhar vírus é a intensa circulação de pessoas pelas redes ferroviária, rodoviária e aérea. Lembrando que a China é o país mais populoso do planeta”.

Wuhan, como área industrial emergente, tem grande população: 11 milhões de habitantes. Como metrópole nacional, a cidade influencia economicamente seu entorno, e apresenta intensos fluxos de pessoas e mercadorias.

Logo, pode-se inferir que, se um vírus é identificado numa área com grande densidade populacional e mobilidade, há forte tendência que este patógeno se espalhe rapidamente por um determinado território.

Além da ligação de Wuhan com outras grandes aglomerações urbanas chinesas, a cidade possui um aeroporto com destinos regulares para países asiáticos e de outros continentes. Consequentemente, por este aeroporto o vírus "viajou" com seus hospedeiros. Se, como em outras épocas, a China fosse uma nação isolada do restante do mundo, a Covid-19 seria, no máximo, uma epidemia.

Oportunamente, um aluno fez a seguinte observação: 
Professor, imagine se essa pandemia tivesse começado na Coreia do Norte, se fosse identificada lá, que eles chamam na televisão de "país mais fechado do mundo". Acho que muito provavelmente a gente nem saberia o que era Covid-19. Não teria se transformado em pandemia, como aconteceu.

No entanto, com os grandes fluxos globais registrados atualmente, a Covid-19, identificada em dezembro de 2019, apenas três meses depois, em março de 2020, já era classificada pela Organização Mundial de Saúde (OMS) como "pandemia global”.

Para ilustrar essa questão, o professor apresentou dois mapas. O primeiro mapa identificava as rotas de espalhamento do novo coronavírus pelo planeta. O segundo mapa mostrava os principais fluxos da globalização.

Após as leituras dos dois mapas, foi possível compreender que o trajeto do patógeno causador da Covid-19 seguiu basicamente o mesmo itinerário dos fluxos da globalização. Começou na China; foi para a Europa (via Oriente Médio); depois América do Norte e. finalmente, chegou à América do Sul.

Ao mostrar um mapa com as interações aéreas globais, o professor observou que o grande número de casos de Covid-19 no Irã, registrados nos primeiros meses da pandemia, estão relacionados ao fato de o país persa ser uma das escalas dos aviões que decolam da China com destino ao continente europeu.

Além do Irã, Itália e Estados Unidos foram dois países bastante afetados pela Covid-19 no início da pandemia. Sobre estes casos, foram exibidas as pirâmides etárias das populações italiana e estadunidense. Assim, foi possível constatar que ambos os países possuem elevado percentual de idosos, contingente que, juntamente com pessoas que possuem comorbidades ou com sistema imunológico debilitado, formam o chamado "grupo de risco" para a pandemia de Covid-19.

Todavia, foi feita uma ressalva por parte do professor:

Só isso (pirâmides etárias) explica os óbitos e casos de Covid-19 na Itália e nos Estados Unidos? Não. O prefeito da cidade italiana de Milão, por exemplo, negava a gravidade da pandemia. Inclusive, fez campanha para que as pessoas seguissem suas vidas normalmente. Da mesma forma, nos Estados Unidos, com o presidente Trump, a ainda havia muito negacionismo no país (PROFESSOR DE GEOGRAFIA).

Em relação à África, o professor apontou que o baixo número de casos de Covid-19 pode ser explicado porque o continente é "praticamente excluído dos principais fluxos de globalização" e, 
recorrendo novamente à análise de pirâmide etária, "apresenta maior número de jovens e baixo percentual de idosos".

\title{
$3^{\circ}$ TÓPICO: COVID-19 NO BRASIL: REFLEXO DA SEGREGAÇÃO SOCIOESPACIAL
}

Diferentemente de outras nações, no Brasil a pandemia de Covid-19 não acometeu com maior intensidade o chamado "grupo de risco". Devido às históricas desigualdades sociais que imperam no país, os maiores percentuais de casos e óbitos ligados à pandemia foram registrados nos estratos inferiores da pirâmide social.

\begin{abstract}
A doença causada pelo coronavírus no Brasil mata mais as pessoas negras e pobres. Com a evolução da epidemia no país, morreram pobres na linha de frente do tratamento à covid-19, trabalhadores de serviços essenciais e informais, trabalhadores que não puderam deixar de trabalhar (...) Racismo, desigualdades sociais, acesso desigual a sistemas de saúde, moradia inadequada e impossibilidade de se isolar colocam população mais vulnerável como a mais afetada pela pandemia (GRAGNANI, 2020).
\end{abstract}

Para ilustrar essa realidade, o professor apresentou aos alunos um mapa do município de São Paulo, que demonstrava como as regiões mais pobres da capital paulista coincidiam com os maiores índices de mortos e contaminados pelo novo coronavírus.

O docente também citou o conceito de segregação socioespacial, que se refere a divisão do espaço urbano por classes sociais:

\begin{abstract}
A separação da cidade por classes sociais nos revela à vulnerabilidade ao vírus. Pobres, pelo menos a maioria, não puderam 'parar' durante a pandemia, não puderam 'ficar em casa'. Estão o tempo todo expostos, seja no transporte público (geralmente superlotado), no trabalho ou mesmo em casa, onde já aglomeravam muita gente (PROFESSOR DE GEOGRAFIA).
\end{abstract}

Em relação à espacialidade da pandemia pelo território brasileiro, o professor destacou os casos registrados nas metrópoles - com destaque para Fortaleza, São Paulo e Rio de Janeiro. Nestas cidades, além da grande concentração populacional, há a chamada "migração pendular", caracterizada pelo intenso fluxo diário de pessoas entre municípios de uma região metropolitana. Tais fatores tornam as principais aglomerações urbanas brasileiras terrenos férteis para a propagação de patógenos como o novo coronavírus. 
Sobre os riscos de contaminação em São Paulo, Codeço et al. (2020, p. 2) enfatizam que a capital paulista "apresenta uma conectividade muito homogênea com todo o território brasileiro, o que indica uma capacidade de exportar de forma simultânea o vírus para as principais capitais e centros urbanos de todas as regiões do país".

Em uma última intervenção, uma aluna perguntou: "professor, qual o papel da Geografia na pandemia?".

Após elogiar o questionamento, o docente afirmou:

\begin{abstract}
Não só na pandemia, mas o papel da Geografia, de maneira geral, é fazer com que a gente tenha uma visão crítica sobre os acontecimentos, não só na escala local, como também na escala global. É entender que algo que acontece na China influencia nosso cotidiano. O papel da Geografia, então, é mostrar que, no mundo globalizado, todos os espaços estão interligados. É não se preocupar só com o que acontece na nossa cidade, mas no nosso país e no mundo. Quem tem uma visão crítica sobre o mundo, não vai ser vulnerável a fake news, não vai cair em corrente de WhatsApp. É ser um cidadão consciente além da sala de aula. É entender que o que se aprende na sala de aula, a gente leva para a vida (PROFESSOR DE GEOGRAFIA).
\end{abstract}

Antes de encerrar a aula, o professor lembrou que, além da dinâmica da propagação do novo coronavírus, a Geografia também nos auxilia a entender as discrepâncias nos ritmos de vacinação contra a Covid-19 pelo mundo.

Para tanto, foi exibido um mapa onde se podia perceber que os países com maiores percentuais de indivíduos imunizados pertenciam, via de regra, ao mundo desenvolvido.

Desse modo, lembrando Souza, Silva e Pimentel (2021), a prática pedagógica aqui relatada comprovou que o uso da linguagem cartográfica é fundamental para ler a pandemia de Covid-19, permitindo assim visualizar o comportamento da disseminação do coronavírus em diferentes escalas espaciais.

\title{
CONSIDERAÇÕES FINAIS
}

A experiência didática apresentada neste artigo possibilitou aos alunos a aquisição de conhecimentos importantes para melhor compreender o contexto do mundo em que vivem. Também demonstrou a abrangência de conteúdos presente na Geografia Escolar. Uma única temática - 
pandemia de Covid-19 - permitiu que docente e discentes abordassem diferentes questões como globalização, geopolítica, urbanização, circulação, meios de transportes e demografia.

Desse modo, se torna possível aos estudantes ultrapassarem a localização da difusão dessa doença e compreender o "comportamento" do vírus, correlacionando-o com o acelerado e desenfreado consumo da sociedade capitalista, o ritmo de urbanização e a fragilidade no cuidado com o meio ambiente.

No entanto, apenas os conceitos e temas presentes na ciência geográfica não esgotam as possibilidades de análise para que os estudantes da educação básica possam entender satisfatoriamente os desdobramentos da pandemia de Covid-19. Nossa realidade é bastante complexa para ser apreendida e estudada por apenas um campo do conhecimento.

Portanto, conceber a pandemia em suas múltiplas facetas, isto é, de maneira holística, significa que devemos recorrer a uma abordagem multidisciplinar que, além da Geografia, envolva conhecimentos e habilidade de outras disciplinas da matriz curricular.

Também é importante refletirmos sobre as relações entre ser humano e seu espaço natural. Nos mais variados âmbitos de nossa sociedade - desde as maiores crenças religiosas, passando pelo sistema econômico e chegando até algumas das principais correntes do pensamento científico moderno - o homem geralmente é concebido como um ser "superior" em relação às demais formas de vida.

Correntes filosóficas como o positivismo acreditavam que, pelo bom uso da razão, os seres humanos seriam capazes de dominar completamente a natureza. Não obstante, para o sistema capitalista - modo de produção vigente na maior parte do planeta -, o meio natural é visto somente como fonte inesgotável de geração de lucros.

No entanto, o que esquecemos (ou fazemos questão de esquecer) é que "nós dependemos totalmente do meio ambiente", e não o contrário. Isso significa frisar que o planeta já existia antes de nós e, provavelmente, ainda continuará existindo quando formos extintos.

\section{REFERÊNCIAS}

ACOSTA, Andre Luis et al. Interfaces à transmissão e spillover do coronavírus entre florestas e cidades. Estudos Avançados, São Paulo, v. 34, n. 99, p. 191-208, ago. 2020 . Disponível em: $<$ http://www.scielo.br/scielo.php?script=sci_arttext\&pid=S0103-40142020000200191\&lng=en\&nrm=iso $>$. Acesso em: 8 maio 2021. 
CALLAI, Helena C. Estudar o lugar para compreender o mundo. In: CASTROGIOVANNI, Antonio Carlos; CALLAI, Helena C.; KAERCHER, Nestor A. (Orgs.). Ensino de geografia: práticas e textualizações no cotidiano. 11 $1^{\mathrm{a}}$. ed. Porto Alegre: Mediação, p. 71-114, 2014.

CODEÇO, Claudia Torres. Estimativa de risco de espalhamento da COVID-19 no Brasil e o impacto no sistema de saúde e população por microrregião, FGV Repositório Digital, mar. 2020. Disponível em: <procc-emap-covid-19-reporte20200317-espalhamento.pdf>. Acesso em: 9 maio 2020.

CUNHA, Chalres Prado. Tecnologias e seus usos durante a pandemia. In: SACRAMENTO, Ana Claudia Ramos; SACRAMENTO, Iomara Barros de Sousa (orgs.). Temas sobre a Covid-19 para o ensino de Geografia. Goiânia: C\&A Alfa Comunicação, p. 49-69, 2021.

GIL, Antonio Carlos. Como elaborar projetos de pesquisa. São Paulo: Atlas, 1988.

GODOY, Arilda Schmidt. Introdução à pesquisa qualitativa e suas possibilidades. RAE - Revista de Administração de Empresas, São Paulo, v.35, n. 2, p. 57-63, 1995.

GRAGNANI, Juliana. Por que o coronavírus mata mais as pessoas negras e pobres no Brasil e no mundo, BBC News Brasil, 12 de julho de 2020. Disponível em: <https://www.bbc.com/portuguese/brasil-53338421>. Acesso em: 9 maio 2021.

LADEIRA, Francisco Fernandes. Fake news em tempos de coronavírus, Coronavírus, Observatório da Imprensa, 31 de março de 2020. Disponível em: $<\mathrm{http} / /$ www.observatoriodaimprensa.com.br/coronavirus/fake-news-em-tempos-de-coronavirus/>. Acesso em: 14 jul. 2021.

LIU, Ping et al. Are pangolins the intermediate host of the 2019 novel coronavirus? Cold Spring Harbor Laboratory, $2020 . \quad$ Disponível em: < https://journals.plos.org/plospathogens/article?id=10.1371/journal.ppat.1008421> . Acesso em: 7 maio 2021.

MUNDO EDUCAÇÃO. Zonas Econômicas Especiais (ZEEs) da China. Disponível em: < https://mundoeducacao.uol.com.br/geografia/zonas-economicas-especiais-zees-china.htm>. Acesso em: 9 maio 2021.

SOUZA, Iomara Barros de; SILVA, Isabela Habib Canaan da; PIMENTEL, Jonas Ramos. Os mapas escolares e a leitura geográfica da pandemia. In: SACRAMENTO, Ana Claudia Ramos; SACRAMENTO, Iomara Barros de Sousa (orgs.). Temas sobre a Covid-19 para o ensino de Geografia. Goiânia: C\&A Alfa Comunicação, p. 30-48, 2021.

UNICEF. Covid-19: Pelo menos um terço das crianças em idade escolar não consegue acessar o ensino a distância durante o fechamento das escolas, diz novo relatório do UNICEF, 2020. Disponível em: https://www.unicef.org/brazil/comunicados-de-imprensa/covid-19-pelo-menos-um-terco-das-criancas-emidade-escolar-não-consegue-acessar-ensino-a-distancia. Acesso em: 06 maio 2021.

VENTURA, Magda Maria. O estudo de caso como modalidade de pesquisa. Revista da Sociedade de Cardiologia do Estado do Rio de Janeiro, Rio de Janeiro, v. 20, n. 5, p. 383-386, set./out. 2007. Disponível em: <http://sociedades.cardiol.br/socerj/revista/2007_05/a2007_v20_n05_art10.pdf >. Acesso em: 9 maio 2021.

XIAO, Kangpeng et al. Isolation and Characterization of 2019-nCoV-like Coronavirus from Malayan Pangolins. Cold Spring Harbor Laboratory, 2020. Disponível em: < https://www.biorxiv.org/content/10.1101/2020.02.17.951335v1>. Acesso em: 7 maio 2021. 
WONG, Antonio C. P. et al. Global Epidemiology of Bat Coronaviruses. Viruses, v.11, 2019. Disponível em: < https://www.ncbi.nlm.nih.gov/pmc/articles/PMC6409556/>. Acesso em: 8 maio 2021.

ZHANG, Tao et al. Probable Pangolin Origin of SARS-CoV-2 Associated with the COVID-19 Outbreak. Current Biology, v.30, 2020. Disponível em: < https://www.sciencedirect.com/science/article/pii/S0960982220303602>. Acesso em: 6 maio 2021. ZHOU, Peng et al. A Pneumonia Outbreak Associated with a New Coronavirus of Probable Bat Origin. Nature, $\quad$ v.579, 2020. Disponível em: https://www.researchgate.net/publication/338998831_A_pneumonia_outbreak_associated_with_a_ new_coronavirus_of_probable_bat_origin $>$. Acesso em: 8 maio $202 \overline{1}$. 